\title{
Evolution of a Prevention Program in Mental Health in a Municipal Therapeutic Service
}

\author{
Milagros de la Rosa Hormiga1, Juan Manuel Herrera Hernández ${ }^{1}$, \\ Candelaria de la Merced Díaz-González², Inmaculada Rodríguez Matos³, \\ María Sandra Marrero Morales ${ }^{4}$ \\ ${ }^{1}$ Universidad de La Laguna, San Cristóbal de La Laguna, Spain \\ ${ }^{2}$ Servicio Canario de la Salud, Las Palmas de Gran Canaria, Spain \\ ${ }^{3}$ Centro de Drogodependencia San Miguel, Tenerife, Spain \\ ${ }^{4}$ Universidad de Las Palmas de Gran Canaria, Las Palmas de Gran Canaria, Spain \\ Email: mhormiga@ull.es
}

Received 23 April 2014; revised 18 May 2014; accepted 14 June 2014

Copyright (C) 2014 by authors and Scientific Research Publishing Inc.

This work is licensed under the Creative Commons Attribution International License (CC BY). http://creativecommons.org/licenses/by/4.0/

(c) (i) Open Access

\section{Abstract}

This study shows the evolution of the demand and assistance in a municipal therapeutic service portfolio in Tenerife. It is a descriptive, qualitative and quantitative study. The sample is made up of 1175 patients assisted in this program in the period of time which ranges from 2005 to 2012. The results show the high demand of this program. Moreover, the results of the intervention coincide with those expected by international and national organisms. Most of the demand is centred on the area of problems called role transitions, followed by those problems grouped in the area of interpersonal conflicts. In the third place, the demand is centred on those problems grouped in the area of interpersonal deficits, and finally on those problems grouped in the category of grieving or mourning problems. It is extremely important to offer this program in the municipal service portfolio as a complementary resource which facilitates the prevention and approach to problems related to mental health in the community because of its high demand, effectiveness and efficacy.

\section{Keywords}

Psychotherapy, Community Psychology, Care Services Portfolio, Prevention Program, Mental Health, Municipal Therapeutic Service

\section{Introduction}

After doing a brief historical research about Community Psychology (CP), it is important to recognize that this

How to cite this paper: de la Rosa Hormiga, M., Hernández, J. M. H., de la Merced Díaz-González, C., Matos, I. R., \& Morales, M. S. M. (2014). Evolution of a Prevention Program in Mental Health in a Municipal Therapeutic Service. Psychology, 5, 979-985. http://dx.doi.org/10.4236/psych.2014.58108 
emerges in United States with the aim of changing the mental health system and creating health assistance networks for the community. However, in Latin America it emerges as a professional response in social contexts associated to social injustice and marginalization (Asún Hamel, 2011: p. 51).

Community Psychology has been defined both from a preventive and participative point of view as regards community mental health and from a global and technically less accurate point of view centred on a radical social change and the development of individuals as historical and cultural subjects (Garfield et al., 1971).

Community Mental Health (CMH) deals with health problems from a community point of view, creating a hybrid also called Clinical Community Psychology, which embraces a set of alternatives to classical clinical strategies. $\mathrm{CMH}$ is considered as a field between individualized clinical work and Community Psychology taken to an extreme (with some relevant differences and making use of its most social and community strategies). It does not differ so much from CP, apart from its limitation to the field of mental health.

$\mathrm{CMH}$, also called Clinical Community Psychology, is a multidisciplinary field, concretely developed in EEUU, combining clinical tradition with a community approach (Gurmanm \& Kniskern, 1978). It comprises a series of intervention strategies such as prevention, crisis intervention, consultation, use of non-professionals, mental health education and promotion, therapeutic community and social therapy (Harris, Kalis, \& Freeman, 1963). Its theoretical and methodological bases include epidemiology, systemic approach, theories of stress and social support, being multidisciplinarity and community participation its operating principles (Sánchez Vidal, 2007: p. 89).

The principles of the so-called Clinical Community Psychology or CCP, according to Desviat and Alonso (2012: pp. 23-24), can be summarized as follows:

- Concern not only about "recovery". The therapeutic act is considered as an action comprising primary health promotion and prevention, secondary prevention and rehabilitation.

- Integration of health care and social and community assistance.

- Consideration about the subjective quality of life of the user and those people around him/her (ethical framework), his/her rights and autonomy. Concepts such as empowerment, resilience and recovery must be taken into account.

- The community is organized to defend the user's rights as regards psychological and mental problems.

- Integration of popular knowledge (traditional medicine, support groups, etc.).

- Recognition of the importance of intersectorial activities among different social, health and community service providers.

Clinical Community Psychology or CMH can be divided into three different models which share a common nucleus: the emphasis on mental health (Luborsky \& Singer, 1975). This fact implies more disadvantages than advantages when the conceptual framework has to be identified because mental health is an element shared by other professionals, approaches and programs (Butcher \& Koss, 1978). From the point of view of Clinical Community Psychology we refer to the practice applied in different fields through operating models (Garfield, 1980). It can be related to the assistance of ill people, addiction recovery, management of anxiety in crisis contexts, proposals of cultural development in neighborhoods, etc. The three models are shown below:

1) Community mental health model: this model focuses on the field of community intervention, understood as a criticism to the way of operating of health services as regards two aspects: 1) criticism to the definitions of mental illness as an intrapsychic entity, focusing on the social level to evaluate the origin of the problem. At the same time, this aspect tries to be fair in the distribution of resources, and 2) to understand the community as an interpersonal communication network (Chacón \& García, 1998). The main methods used in this model are crisis intervention, brief therapy and consultation in mental health, focusing the attention on empirical and epidemiological evidence as regards impact assessment of programs (Butcher \& Koss, 1978). The main conceptual elements of this model are positive mental health and preventive and promotional emphasis (de la Rosa Hormiga \& Díaz-González, 2012).

2) Community behavioral model: This model is based on achieving long-lasting changes at a behavioral level in individuals and groups of individuals, avoiding inadequate practices and creating more adaptive ones through operative strategies of self-control and social learning (Philips \& Wiener, 1966). Therefore, this implies the inclusion of those programs which follow non-professional orientation (for instance, members of the community), creating new ways of community intervention related to health.

3) Psychosocial stress model: Dohrenwend (1978) states that all community interventions would be focused on "undermining the process through which psychosocial stress produces both mental and social disorders (Av- 
net, 1965). Nevertheless, due to the complexity of this process, it can be studied from different points of view (Muench, 1965). This would explain the differences among the activities developed by community psychologists". The main interest of this model refers to the fusion of personal and environmental factors which affect behavior, being its main deficiency the difficulty that such fusion shows in order to incorporate structural and macrosocial elements which determine the individual's life.

Within the local government services, the Law regulating the Bases of the Local Government (1985) establishes in article 25 the competences of municipalities and determines the specific competences related to Social Services Assistance.

The programs and services offered are functionally structured in two levels:

- Primary social assistance or community-based general social services, which are responsibility of the local governments and give information, orientation and support. They are considered as the entrance door to Public Social Services System.

- Specialized programs (secondary and specific): They focus on sectors such as childhood, family, young people, the elderly, handicapped people, gender equality and social protection for women, socially and economically disadvantaged people, immigrants and emigrants, etc.

Although, according to Avila (2002), the offer of psychotherapy programs in public services provided, public financing and insurance coverage are increasing, the current legislation only forces the local government services through the Law regulating the Bases of the Local Government (1985; art. 25) to provide primary social care or general or specialized social services, addressed to specific sectors in society, where psychosocial assistance is provided.

Candelaria Townhall offers in its municipal service portfolio this additional service. Although it is not a compulsory social service according to the current legislation, people responsible for the Social Policy, basing their assumptions on the results obtained and the studies which have been performed, consider that this type of services are complementary to psychosocial intervention and can be coordinated in the area of intervention with those people who are assisted in the different health resources (primary and specialty care), in order to contribute to the development of primary, secondary and tertiary prevention in the community (Caplan, 1964; Sánchez Vidal, 2007; López-Cábanas \& Chacón, 1997).

The medical team in the psychosocial service is made up by two professionals: a graduate social worker, with a university expert degree in psychotherapy, family intervention and personality disorders and a psychologist.

Objectives: To show the results in the evolution of the psychosocial unit in Candelaria Townhall, from its beginning in June 2005 to December 31st in 2012 (period which ranges from 2005 to 2012).

\section{Method}

The subjects studied are those who have attended the Municipal Psychosocial Office through the Municipal Social Services, the Primary Health Care Centre, the municipal resources, the patient's own initiative and other resources (Mental Health, NGOs, associations, etc.). A number of 1175 individuals who have been assisted in MTS (Municipal Therapeutic Service) have been selected for this study.

Method and design: This is a descriptive, qualitative and quantitative study. The variables which have been studied are sex, age, demand, derivation or remittent, problem treated in the service, discharges, work absence for illness, withdrawal, group sessions, participants and reports.

Procedure: Evaluation reports from 2005 to 2012 have been studied to do this research.

Instruments: In order to perform this report, evaluation reports from 2005 to 2012 have been taken into account.

\section{Results}

Although the MTS is not a compulsory service in the Law regulating the Bases of the Local Government, its consolidation in the municipal service portfolio is remarkable due to the results obtained. This consolidation is shown both through the increase of the users' demand and through the use of the different professions in the municipality as regards its process of intervention and other municipal resources. The report shows that 1175 people have received psychotherapeutic assistance. 664 patients (56.51\%) sought medical care recommended by the experts in the Social Services in the municipality, 320 patients $(27.23 \%)$ attended on their own initiative, $7.06 \%$ were referred by the Councilor responsible for Social Services, 83 patients (3.15\%) were referred to the 
service by the Mental Health Service; 37 users and $6.40 \%$ (71) by other municipal resources. The evolution of the demand in consultations with the passing of time and the total amount of consultations increased to 6143 . 4782 patients were assisted from the total demand obtained. The coverage of care in the period of time studied was $77.87 \%$, indicating a high degree of treatment coverage. From the total amount of patients $(1361,22.15 \%)$ who were not assisted, 63.85\% (869) changed their medical appointment and 36.15\% (492) did not visit the office for consultation and, moreover, they did not cancel it. From the amount of patients who did not cancel the medical appointment, 350 patients (71.13\%) asked again for a medical appointment and were finally assisted, whereas 142 patients (28.86\%) did not seek medical advice anymore.

The demand of this service has increased with the passing of time. For this reason, this service has created a waiting list which is processed by Social Services, taking into account, as the main criteria, the order of arrival and those patients under 18 years old. This high demand has been processed with the same resources (two professionals) and days of assistance (four). The global cover ture in MTS shows an average of $83.54 \%$ from the total amount of the demand presented.

It must be taken into consideration that from the total amount of patients assisted (1175), 1007 (85.7\%) are women, whereas 168 patients (14.3\%) are men. 1033 (85.36\%) are adult patients, whereas $142(12.09 \%)$ are under 18 years old. Most of the patients assisted are community residents (1075 patients, 91.49\%) whereas 100 patients (8.51\%) live in the municipality but are not community residents (they come mainly from Latin American countries). As regards the access to the service, it must be taken into account that most of the users are referred by the experts or technicians of the Municipal Social Services or attend on their own initiative.

The situations which have been assisted in TMS can be divided into the following areas:

- Role transitions (677 patients, 57.62\%).

- Interpersonal disputes (336 patients, 28.60\%): interpersonal deficits (83 patients, 7.06\%) and separation and mourning (79 patients, 6.72\%).

Most of the demand is placed on the area of problems called role transitions (desired and accidental vital changes: divorce, economic changes, limitations due to physical or emotional disabilities, occupational changes, etc.), followed by those demands referred to as "interpersonal disputes" (non-reciprocal relationships with people who are important in the individual's life such as spouse, family, etc.). The third place in the demand is for those problems related to separation and mourning (separation/loss, deaths, reappearance of previous mourning, etc.).

The number of patients who are treated increases every year, taking into account that the demand can take place any time during the year. This situation implies that many users who start their treatments at the end of the last trimester in the year, continue the treatment the following year. These patients are added to the new patients assisted. Therefore, the number of patients increases each year due to this situation. On the other hand, there are users who, although they are discharged from the service, ask again for a medical appointment due to other problems. It is significant the referral to more adequate resources according to the demand and the low amount of patients who abandon their treatment. This fact shows the high adherence to the treatment the population assisted shows and the right referral from the municipal resources to this service.

There is a group of users (22.98\%) who are still being treated. This number varies according to the period of the year in which they ask for the service (taking into account that the type of problem presented and the specific psychotherapeutic treatment require at least six-eight months of assistance, depending on the patient treated and the variables related to the management of the problem: the length of the treatment, previous treatments in other areas or resources, family support, among other relevant aspects). The onset of the treatment in the last trimester of the year implies that patients must continue with their treatment the following year. Therefore, these patients, as it was stated before, are added to the new patients assisted. A group of patients (6.22\%) reinitiate a treatment asking for a new demand. These patients show the following characteristics: individuals suffering from chronic degenerative diseases who need continuous support as their disease progresses (impairment in social interaction, cognitive impairment, among other important aspects), to be able to reduce the discomfort produced by their disease or impairment.

The frequency of therapeutic discharges in MTS has remained stable in the period of time that has been studied and the demand has gradually increased as the service becomes established in the Social Service Portfolio.

The treatment drop-out rate (adherence) is low (4.85\%, 57 patients). However, the frequency of therapeutic discharges over the total demand from 2005 to 2012 represents a percentage of 57.35\%, varying this percentage according to the number of users who seek medical treatment. 
Two psychoeducational groups have been created in MTS. The first group is made up of female patients (group 1) and the second group is constituted by individuals in situations of risk or social exclusion (group 2). Each session in both psycho educational groups and their participants are recorded. The second group started to operate in mid-2011 because of its high local demand.

Many reports have been provided by MTS as regards the evolution, assessment, intervention and evaluation, as part of the operational process and organization of a service like this.

Since 2010, waiting lists have been created due to the high demand in this service. This demand has increased with the passing of time.

\section{Discussion}

The evolution of the demand of the service in the period of time analyzed shows both a consolidation of the service itself in the therapeutic municipal service portfolio and its use by the citizens. The average consultation time per patient has increased with the passing of time, being the onset of the economic crisis the period with the highest demand and complexity related to problems and continuation of the treatments prescribed to patients. Percentage increase in demand in the municipal therapeutic service remains constant in a $62 \%$, taking into account the municipal effort and the effort of technicians to be able to respond to a considerable increase in the demand with the same days of assistance, the same professionals and increase of new activities offered in the service.

The access of the users to this therapeutic service is mainly through derivation from the municipal social services, followed by the user's personal initiative and other resources of the community. These results show the use and relevance of this service in the municipal portfolioto approach to those problems which affect the users (social and emotional problems), who need specialized psychotherapeutic assistance for their demands.

As regards the users, most of the individuals who are assisted are female adult users who live in the city.

With relation to the demand of the problems and to facilitate its grouping taking into account the different areas of problems which are diagnosed by means of the classification of diagnostic criteria established by the scientific community (DSM-IV-R and ICD-10 and the use of psychometric and projective tests and other diagnostic and intervention techniques), most of the demand is placed on the area of problems called role transitions (it refers to desired and accidental vital changes: divorce, economic change, limitations due to physical disability, emotional, psychological or psychopathologic disorders, occupational change, and so on), followed by the demand referred to those problems related to interpersonal disputes (it refers to emotional and psychological reactions due to non-reciprocal relationships with people who are important in the individual's life such as spouse, family, children, etc.). The third place in the demand is for those problems which have to do with the area of interpersonal deficits (difficulties to establish and maintain relationships which produce solitude and social isolation), and finally problems related to separation and mourning (separation/loss, death of people who are important in the life of the individual, reappearance of a previous mourning, etc.).

It is important to take into account that the increase in the demand of psycho-emotional problems in the $\mathrm{Mu}-$ nicipal Therapeutic Service, coincides with the predictions of international and national organisms (WHO, 2011, 2012, Ministry of Health and Consumer Affairs, 2010, 2011, the Canary Health Care Service, 2010, 2011, 2012), as regards the population's mental health. According to these organisms and several epidemiological studies, this demand is related to factors such as social stressors, weakness of social networks, lack of prevention in the community mental health, etc.

As regards the users who were assisted in the service and taking into account the results obtained, it is important to point out both the low psychotherapeutic treatment dropout and the discharge rates, which show that this service has been highly valued by the users.

The Municipal Therapeutic Service offers two psycho-educational groups: the first one is focused on women who live in the municipal area and the second one appears as a demand proposed by the experts or technicians of the Social Services, addressed to people in situations of risk and/or social vulnerability perceiving social security benefits. Moreover, evaluation and evolution reports of the users who are assisted and annual, biannual and monthly evaluation reports of results, which are given to the people responsible for the Social Services area, are submitted.

It must be taken into account the increase of the waiting lists, due to the use of the service as regards techniques and other community and extra-community resources of residents in the municipal area. The initiative of the users has also increased. 
As regards the results and their analysis, the Municipal Therapeutic Service can be considered as a consolidated resource in the Municipal Service Portfolio. In addition to its results, the following aspects can be considered:

Its efficacy: it refers to the capacity to solve a problem (disappearance of the emotional and/or psychological problems), obtaining $57.35 \%$ of discharge rates each year over the total number of people assisted.

Its effectiveness: it refers to the relation between the results obtained (demand, patients treated, discharges, withdrawal, groups, reports), and the resources used (two psychotherapists working four days a week in the afternoon)

Its efficiency: it refers to the cost-effectiveness it is supposed to have, knowing that the results of the efficiency, if compared with other healthcare resources, is above average (this hypothesis needs verification, although it is assumed from a technical point of view).

The MTS appears to be in the municipal setting a necessary and complementary resource to the Portfolio of Social Municipal Services.

\section{Recommendations}

According to the results obtained in this evaluation report, the following recommendations to improve and organize the therapeutic service in the municipality have been established:

- To continue offering in the municipal portfolio the therapeutic service as an additional resource which facilitates the prevention and the approach of those mental health problems in the community.

- To value the importance of creating a law to regulate the costs of consultations in the Municipal Therapeutic Service for the users, considering socioeconomic criteria in each case.

- To regulate the service creating a list of the supply and demand for jobs to guarantee its consolidation in the municipal portfolio.

- To perform a cost-effectiveness analysis of the therapeutic service in the municipality, comparing it with other systems of psychotherapy in the community (e.g. mental health).

- To promote the prevention and promotion of hygiene or mental health in the community from the municipal social services.

\section{References}

Asún Hamel, M. (2011). Introducción a la Psicología Comunitaria: Algunos presupuestos teóricos. In I. Fernández, J. F. Morales, \& F. Molero (coords.), Psicología de la Intervención Comunitaria. Bilbao: Desclée.

Avila, A. (2002). ¿Hacia dónde va la psicoterapia? Reflexiones sobre las tendencias de evolución y los retos profesionales de la psicoterapia. Versión revisada de la conferencia pronunciada en las II Jornadas de la Federación Española de Asociaciones de Psicoterapeutas (FEAP), San Juan, 12-14 April 2002.

Avnet, H. H. (1965). How Effective Is Short-Term Therapy? In L. R. Wolberg (Ed.), Short-Term Psychotherapy. New York: Grune and Stratton.

Butcher, J. N., \& Koss, M. P. (1978). Research on Brief and Crisis-Oriented Therapies. In S. L. Garfield, \& A. E. Bergin (Eds.), Handbook of Psychotherapy and Behavior Change (2nd ed.). New York: Wiley and Sons.

Chacón, F., \& García, M. J. (1998). Modelos teóricos en psicología comunitaria. In A. Martín González (Ed.), Psicología Comunitaria: Fundamentos y aplicaciones (pp. 31-47). Madrid: Síntesis.

de la Rosa Hormiga, M., \& Díaz-González, C. (2012). Modelo de Programa de Prevención de la Salud mental en la comunidad. Ed. M.R.H, Depósito Legal, Tenerife.

Desviat, M., \& Moreno, A. (2012). Principios y objetivos de la salud mental comunitaria. In M. Desviat, \& A. Moreno (Eds.), Acciones de Salud Mental en la Comunidad. Madrid: AEN.

Dohrenwend, B. S. (1978). Social Stress and Community Psychology. American Journal of Community Psychology, 6, 1-14. http://dx.doi.org/10.1007/BF00890095

Garfield, S. L. (1980). Psychotherapy and Eclectic Approach. New York: Wiley and Sons.

Garfield, S. L. et al. (1971). Evaluation of Outcome in Psychotherapy. Journal of Consulting and Clinical Psychology, 37, 307-313.

Gurmanm, A. S., \& Kniskern, D. P. (1978). Research on Marital and Family Therapy. In S. L. Garfield, \& A. E. Bergin (Ed.), Handbook of Psychotherapy and Behavior Change (2nd ed.). New York: Wiley and Sons.

Harris, M. R., Kalis, B., \& Freeman, E. H. (1964). An Approach to Short-Term Psychotherapy. Mind, 2, 198-206. 
Harris, M. R., Kalis, B., \& Freeman, E. H. (1963). Precipitating Stress: An Approach to Brief Therapy. American Journal of Psychotherapy, 17, 465-471.

Luborsky, L., \& Singer, B. (1975). Comparative Studies of Psychotherapies: Is It True That Everyone Has Won and All Must have Prizes? Archives of General Psychiatry, 32, 995.

Muench, G. A. (1965). An Investigation of the Efficacy of Time-Limited Psychotherapy. Journal of Counseling Psychology, 12, 294-299. http://dx.doi.org/10.1037/h0022585

Philips, E. L., \& Wiener, D. N. (1966). Short Term Psychotherapy and Structural Behavior Change. New York: McGrawHill.

Sánchez Vidal, A. (2007). Manual de Psicología Comunitaria: Un enfoque integrado. Madrid: Pirámide. 